Compared to monotherapy, combination therapy was associated with a lower drug failure (crude HR 0.75 [95\% Cl 0.68-0.82]; adjusted HR 0.78 [95\% Cl 0.70-0.86]; $\mathrm{p}<0.0001$ )

In patients in monotherapy, considering ETA as reference and adjusting for the above mentioned clinical characteristics, the HR for bDMARD failure was 1.32 for ADA (95\% Cl 1.07-1.63) and 2.38 for INF (95\% Cl 1.85-3.07).

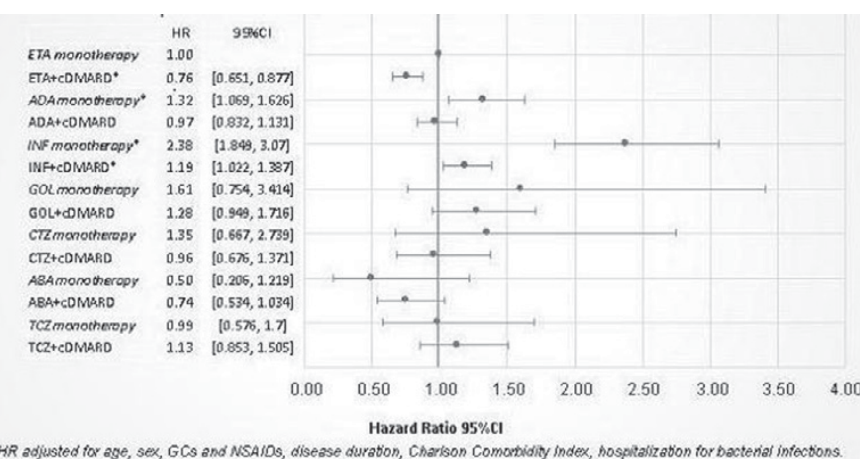

Conclusions: Monotherapy with bDMARDs is consistenly associated with lower retention rate in first-line therapy for anti-TNF drugs. Comparing bDMARDs administered in monotherapy, INF and ADA show a higher risk of withdrawal than ETA. Real life data support the currently recommended use of bDMARDs in association to csDMARDs.

References:

[1] Souto et al. Rheum (Oxford)2016;55(3):523-34.

[2] Choy et al. Rheum (Oxford)2016; 21.

Acknowledgements: None declared.

Disclosure of Interest: None declared

DOI: 10.1136/annrheumdis-2017-eular.5236

\section{FRI0213 COMPARATIVE EFFECTIVENESS OF ABATACEPT, RITUXIMAB TOCILIZUMAB AND ANTI-TNF BIOLOGICAL DMARDS IN RA: RESULTS FROM THE NATIONWIDE SWEDISH REGISTER}

T. Frisell ${ }^{1}$, M. Dehlin ${ }^{2}$, D. Di Giuseppe ${ }^{1}$, N. Feltelius ${ }^{3}$, A. Kastbom ${ }^{4}$ C. Turesson ${ }^{5}$, J. Askling ${ }^{1}$ on behalf of the ARTIS Study Group. ${ }^{1}$ Karolinska Institutet, Stockholm; ${ }^{2}$ Sahlgrenska Academy, University of Gothenburg,

Göteborg; ${ }^{3}$ Medical Products Agency, Uppsala; ${ }^{4}$ Rheumatology/AIR, Linköping;

${ }^{5}$ Rheumatology, Department of Clinical Sciences, Malmö, Lund University,

Malmö, Sweden

Background: Many current guidelines rank abatacept (ABA), rituximab (RTX), tocilizumab (TOC), and the TNFi bDMARDs as equal in effectiveness for the treatment of RA, at least as second line therapies. This is mainly based on evidence from separate RCTs, with few direct comparisons and limited comparative effectiveness data from clinical practice.

Objectives: To describe outcomes in clinical practice among RA patients starting different bDMARDs as first bDMARD, and after switch from initial TNFi.

Methods: The Swedish Rheumatology Register was linked to nationwide registers with data on demographics and medical history. We included all patients with RA starting a first ever bDMARD, or switching to a new bDMARD after a TNFi as first bDMARD, in 2010 - 2014, with follow-up through 2015. Effectiveness was assessed at 1 year ( \pm 90 days) after starting therapy, and measured as 1 ) the proportion remaining on therapy, or the proportion remaining on therapy and with 2) Good EULAR response, 3) HAQ improvement $>0.2$, 4) no swollen or tender joints. Relative response was estimated with log-binomial regression adjusting for potential confounders.

Results: Patients starting non-TNFi were older than those starting a TNFi, had lower socioeconomic status, and more often a history of diseases including malignancy, serious infections, and diabetes. After switch from TNFi, those starting non-TNFi also had higher disease activity.

Non-TNFi were associated with better drug survival and higher proportion reaching response outcomes compared to TNFi as first bDMARD. After switch from TNFi, RTX and TOC, but not ABA, were associated with significantly better drug survival and response. Differences remained after adjusting for identified potential confounders.

Conclusions: Despite channeling of older and sicker individuals to non-TNFibDMARDs, treatment outcomes were in general better in these groups, particularly for TOC and RTX. In interpreting this, the risk of residual confounding should be remembered, and that we did not include safety or long term outcomes.

Acknowledgements: The ARTIS registry has been, or is, supported by agreements with Abbvie, BMS, MSD, Pfizer, Roche, Samsung, and UCB.

Disclosure of Interest: T. Frisell: None declared, M. Dehlin: None declared, D. Di Giuseppe: None declared, N. Feltelius: None declared, A. Kastbom Consultant for: Bristol-Myers Squibb, Pfizer, Roche, UCB, Paid instructor for: Bristol-Myers Squibb, Pfizer, Roche, UCB, C. Turesson Grant/research support from: Abbvie, Pfizer, Roche, Consultant for: MSD, Pfizer, Roche, Paid instructor for: Abbvie, Bristol-Myers Squibb, Janssen, MSD, Pfizer, Roche and UCB, J. Askling Grant/research support from: Abbvie, UCB, Pfizer, Merck, Samsung, Roche, Lilly

DOI: 10.1136/annrheumdis-2017-eular.1307

\section{FRI0214 LONG-TERM EFFICACY AND SAFETY OF SIRUKUMAB IN PATIENTS WITH ACTIVE RHEUMATOID ARTHRITIS DESPITE ANTI-TUMOR NECROSIS FACTOR THERAPY: RESULTS OF THE RANDOMIZED, PHASE 3 SIRROUND-T STUDY}

Y. Tanaka ${ }^{1}$, D. Aletaha ${ }^{2}$, P. Agarwal ${ }^{3}$, R. Kurrasch ${ }^{4}$, P.P. Tak ${ }^{5}$, S. Popik ${ }^{3}$. ${ }^{1}$ Department of Internal Medicine, University of Occupational and Environmental Health, Kitakyushu, Japan; ${ }^{2}$ Division of Rheumatology, Medical University of Vienna, Vienna, Austria; ${ }^{3}$ Janssen Research \& Development, LLC, Spring House, PA; ${ }^{4}$ GlaxoSmithKline, Collegeville, PA, United States; ${ }^{5}$ GlaxoSmithKline, Stevenage, United Kingdom

Background: Sirukumab, a selective, high-affinity human monoclonal antibody to the interleukin-6 (IL-6) cytokine, is under development for rheumatoid arthritis (RA) and other diseases.

Objectives: To evaluate long-term efficacy and safety of sirukumab in patients (pts) with RA refractory or intolerant to anti-tumor necrosis factor (TNF) agents.

Methods: This phase 3 study included pts $\geq 18$ years with moderate to severe active RA, and a lack of benefit to $>1$ anti-TNF or intolerance to $\geq 2$ anti-TNFs. Eligible pts were initially randomized $1: 1: 1$ to sirukumab subcutaneous (SC) $50 \mathrm{mg}$ q4w, sirukumab SC $100 \mathrm{mg}$ q2w, or placebo SC q2w for 24 wks. Placebo-treated pts with $<20 \%$ improvement in tender and swollen joints at Wk 18 (early escape $[E E])$ and those remaining on placebo at Wk 24 (crossover) were re-randomized to sirukumab through Wk 52. Efficacy endpoints included ACR response, HAQ-DI scores, DAS28 (CRP) remission rates, and SF-36 scores. Results are presented for these key endpoints at Week 52 .

Results: 878 pts were initially randomized to placebo $(n=294)$, sirukumab $50 \mathrm{mg}$ q4w $(n=292)$, or sirukumab $100 \mathrm{mg}$ q2w $(n=292)$. Of placebo-treated pts, 94 met EE criteria at Wk 18 and 158 crossed over at Wk 24 and were re-randomized to sirukumab. $60 \%$ of pts had received $\geq 2$ prior biologics, including non-TNFtargeted biologics. RA signs and symptoms and patient-reported outcomes (PROs [SF-36 scores]) improved significantly with sirukumab versus placebo through Wk 24. Improvements were maintained through Wk 52 with no dose response (Table 1). Through Wk 52 in the combined sirukumab $50 \mathrm{mg} \mathrm{q} 4 \mathrm{w}$ and $100 \mathrm{mg}$ q2w groups, respectively, an adverse event $(\mathrm{AE})$ was reported for $79.6 \%$ and $81.3 \%$ of pts and a serious $A E$ was reported for $14.2 \%$ and $13.2 \%$ of pts; injection-site reactions and alanine aminotransferase increases were the most commonly reported AEs. Conclusions: In this population intolerant or refractory to anti-TNFs/other biologics, sirukumab SC 50mg q4w and $100 \mathrm{mg}$ q2w were well tolerated and reduced signs and symptoms of $R A$ and improved PROs through 52 wks of treatment, also among pts who switched from placebo to sirukumab.

Disclosure of Interest: Y. Tanaka Grant/research support from: MitsubishiTanabe, Takeda, Daiichi-Sankyo, Chugai, Bristol-Myers, MSD, Astellas, Abbvie, and Eisai, Speakers bureau: Abbvie, Chugai, Daiichi-Sankyo, Bristol-Myers, Mitsubishi-Tanabe, Astellas, Takeda, Pfizer, Teijin, Asahi-kasei, YL Biologics, Sanofi, Janssen, Eli Lilly, and GlaxoSmithKline, D. Aletaha Grant/research support from: AbbVie, Pfizer, Grünenthal, Merck Medac, UCB, Mitsubishi/Tanabe, Janssen, and Roche, Consultant for: AbbVie, Pfizer, Grünenthal, Merck Medac, UCB, Mitsubishi/Tanabe, Janssen, and Roche, P. Agarwal Shareholder of:

Abstract FRI0213 - Table 1. Status at 12 months among all patients with RA initiating a biologic DMARD 2010-2014 in Sweden

\begin{tabular}{|c|c|c|c|c|c|c|c|}
\hline & \multirow{2}{*}{$\begin{array}{c}\text { TNFi } \\
\%\end{array}$} & \multicolumn{2}{|c|}{ RTX } & \multicolumn{2}{|c|}{ TOC } & \multicolumn{2}{|c|}{ ABA } \\
\hline & & $\%$ & $\mathrm{RR}^{\dagger}$ & $\%$ & $\mathrm{RR}^{\dagger}$ & $\%$ & $\mathrm{RR}^{\dagger}$ \\
\hline First bDMARD & $\mathrm{N}=5568$ & \multicolumn{2}{|c|}{$\mathrm{N}=654$} & \multicolumn{2}{|c|}{$\mathrm{N}=202$} & \multicolumn{2}{|c|}{$\mathrm{N}=240$} \\
\hline On drug & 68.4 & 87.8 & $1.34(1.27-1.41)$ & 75.5 & $1.20(1.09-1.31)$ & 77.7 & $1.15(1.05-1.27)$ \\
\hline On drug + EULAR Good resp. & 26.1 & 31.1 & $1.42(1.19-1.69)$ & 53.1 & $2.03(1.70-2.42)$ & 34.3 & $1.37(1.10-1.72)$ \\
\hline On drug + HAQ Improvement & 26.7 & 39.2 & $1.64(1.40-1.93)$ & 45.0 & $1.54(1.27-1.87)$ & 36.8 & $1.37(1.09-1.71)$ \\
\hline On drug +28 Joint count $=0$ & 20.3 & 22.4 & $1.13(0.89-1.43)$ & 30.9 & $1.60(1.21-2.11)$ & 22.8 & $1.26(0.91-1.74)$ \\
\hline Switch from TNFi & $\mathrm{N}=1840$ & \multicolumn{2}{|c|}{$\mathrm{N}=408$} & \multicolumn{2}{|c|}{$\mathrm{N}=320$} & \multicolumn{2}{|c|}{$\mathrm{N}=256$} \\
\hline On drug & 57.7 & 80.2 & $1.48(1.37-1.60)$ & 73.0 & $1.36(1.23-1.49)$ & 65.1 & $1.11(0.98-1.26)$ \\
\hline On drug + EULAR Good resp. & 11.4 & 24.0 & $1.87(1.41-2.49)$ & 36.8 & $3.06(2.37-3.94)$ & 14.6 & $1.16(0.76-1.76)$ \\
\hline On drug + HAQ Improvement & 16.6 & 34.3 & $1.85(1.49-2.30)$ & 32.4 & $1.71(1.33-2.19)$ & 20.4 & $1.10(0.78-1.53)$ \\
\hline On drug +28 Joint count $=0$ & 12.3 & 20.8 & $1.96(1.43-2.70)$ & 19.9 & $2.12(1.48-3.02)$ & 11.2 & $0.86(0.48-1.52)$ \\
\hline
\end{tabular}

${ }^{\dagger}$ Adj. for region, sex, age, birth country, RF, dis. dur., HAQ, DAS28, co-medication, recent history of malignancy, infection, SSRI, and hospital days last 5 yrs. 
Abstract FRI0214 - Table 1. Key Endpoints at Wk 52

\begin{tabular}{|c|c|c|c|c|c|c|}
\hline \multirow[t]{2}{*}{ Endpoints } & \multicolumn{3}{|c|}{ Sirukumab $50 \mathrm{mg} \mathrm{q} 4 \mathrm{w}$} & \multicolumn{3}{|c|}{ Sirukumab $100 \mathrm{mg} \mathrm{q} 2 \mathrm{w}$} \\
\hline & $\begin{array}{c}\text { Placebo to } \\
50 \mathrm{mg} \mathrm{q} 4 \mathrm{w}(\mathrm{n}=124)\end{array}$ & $50 \mathrm{mg} \mathrm{q} 4 \mathrm{w}(\mathrm{n}=235)$ & $\begin{array}{c}\text { Combined } \\
50 \mathrm{mg} \mathrm{q} 4 \mathrm{w}(\mathrm{n}=359)\end{array}$ & $\begin{array}{c}\text { Placebo to } \\
100 \mathrm{mg} \mathrm{q} 2 \mathrm{w}(\mathrm{n}=123)\end{array}$ & 100 mg q2w $(n=241)$ & $\begin{array}{c}\text { Combined } \\
100 \mathrm{mg} \mathrm{q2w}(\mathrm{n}=364)\end{array}$ \\
\hline ACR20 response, $\mathrm{n}(\%)$ & $68(54.8)$ & $127(54.0)$ & $195(54.3)$ & $71(57.7)$ & $145(60.2)$ & $216(59.3)$ \\
\hline ACR50 response, $\mathrm{n}(\%)$ & $41(33.1)$ & $74(31.5)$ & $115(32.0)$ & $38(30.9)$ & $77(32.0)$ & $115(31.6)$ \\
\hline HAQ-DI change from baseline, mean (SD) & $-0.30(0.55)$ & $-0.39(0.58)$ & $-0.36(0.57)$ & $-0.43(0.51)$ & $-0.43(0.60)$ & $-0.43(0.57)$ \\
\hline DAS28 (CRP) <2.6, n (\%) & $36(29.0)$ & $63(26.8)$ & 99 (27.6) & $42(34.1)$ & $71(29.5)$ & $113(31.0)$ \\
\hline \multicolumn{7}{|l|}{ SF-36 summary scores } \\
\hline PCS change from baseline, mean (SD) & $4.47(7.70)$ & $6.33(7.23)$ & $5.69(7.44)$ & $5.45(7.22)$ & $5.98(7.25)$ & $5.80(7.24)$ \\
\hline MCS change from baseline, mean (SD) & $3.64(8.48)$ & $5.19(10.84)$ & $4.65(10.10)$ & $5.60(10.62)$ & $4.46(10.45)$ & $4.85(10.51)$ \\
\hline
\end{tabular}

Janssen Research \& Development, LLC, Employee of: Janssen Research \& Development, LLC, R. Kurrasch Shareholder of: GlaxoSmithKline, Employee of: GlaxoSmithKline, P. Tak Shareholder of: GlaxoSmithKline, Employee of: GlaxoSmithKline, S. Popik Shareholder of: Janssen Research \& Development, LLC, Employee of: Janssen Research \& Development, LLC

DOI: 10.1136/annrheumdis-2017-eular.6486

\section{FRI0215 COMPARATIVE EFFICACY AND RETENTION RATE OF TOCILIZUMAB AND TNF INHIBITORS USED IN COMBINATION WITH METHOTREXATE AS FIRST-LINE BIOLOGIC THERAPY IN RHEUMATOID ARTHRITIS: DATA FROM A MULTICENTRE OBSERVATIONAL REGISTRY}

E.G. Favalli ${ }^{1}$, M. Biggioggero ${ }^{1}$, P. Sarzi Puttini ${ }^{2}$, F. Atzeni ${ }^{2}$, E. Fusaro ${ }^{3}$, V. Grosso ${ }^{4}$, R. Pellerito ${ }^{5}$, R. Gorla ${ }^{6}$, C. Bazzani ${ }^{6}$, A. Marchesoni ${ }^{1}$, R. Caporali ${ }^{4}$. ${ }^{1}$ Department of Rheumatology, Gaetano Pini Institute; ${ }^{2}$ Rheumatology Unit, University Hospital L. Sacco, Milano, ${ }^{3}$ Rheumatology, Azienda Ospedaliera Universitaria Città; della Salute e della Scienza, Torino: ${ }^{4}$ Rheumatology, University of Pavia, IRCCS Policlinico San Matteo Foundation, Pavia; ${ }^{5}$ Rheumatology, Ospedale Mauriziano, Torino; ${ }^{6}$ Rheumatology Unit, Spedali Civili, Brescia, Italy

Background: Despite a demonstrated superiority of interleukin- 6 over tumour necrosis factor (TNF) blockade when used as monotherapy, the choice of the first biologic agent (bDMARD) for treating rheumatoid arthritis (RA) in combination with methotrexate (MTX) is still a challenge for rheumatologist.

Objectives: To retrospectively evaluate in a multicentre observational cohort of Northern Italy (the LORHEN registry) the 6- and 12-month comparative drug survival and remission rate of tocilizumab (TCZ) and TNF inhibitors (TNFis) used as first bDMARD in combination with MTX.

Methods: All RA patients treated with TCZ or a TNFi as first-line bDMARD with at least 12-month follow-up were selected from the LORHEN registry. The analysis was limited to the period from January 2009 to May 2016 and to patients receiving either TCZ or TNFi in combination with MTX, excluding bDMARD monotherapy. Six- and 12-month clinical remission rate was defined as achievement of disease activity score 28 calculated by using erythrosedimentation rate (DAS28-ESR) $<2$.6. Drug persistence was calculated by Kaplan-Meier method. The comparison between treatment subgroups was performed by a chi-square test for remission data and by a log-rank test for drug survival. Moreover, DAS28-ESR remission rate has been corrected for drug discontinuation by using the LUNDEX formula (1).

Results: The overall study population included 591 patients (female $77.3 \%$, mean age [ \pm standard deviation, SD] $54.2 \pm 13.2$ years, mean disease duration $[ \pm S D]$ $7.4 \pm 7.7$ years, positive rheumatoid factor $67.5 \%$, positive anti-citrullinated peptide antibodies $77.6 \%$, mean baseline DAS28-ESR 5.1 1.2$)$ treated with TCZ $(n=61)$ or TNFis ( $n=530$; infliximab 43 , adalimumab 163, etanercept 195 , golimumab 60 , certolizumab pegol 69). Baseline characteristics were similar in the two groups, with the exception of mean age (TCZ 58.2 vs TNFis 53.7 years; $p=0.021$ ). No significant differences $(p=0.361)$ emerged in the 6 - (TCZ $88 \%$ vs TNFis $84.3 \%$; $p=0.752$ ) and 12 -month (TCZ $76.4 \%$ vs TNFis $71.5 \%$;) retention rate. Clinical remission was achieved in overall $35.7 \%$ patients at 6 months (TCZ 59\% vs TNFis $33 \% ; p<0.001$ ) and in $36.8 \%$ patients at 12 months (TCZ $58.8 \%$ vs TNFis $34.5 \%$; $\mathrm{p}<0.001)$. Similar trends were observed after correction by LUNDEX formula at 6 (TCZ $51.9 \%$ vs TNFis $27.8 \%$ ) and 12 months (TCZ $44.9 \%$ vs TNFis $24.6 \%$ ).

Conclusions: Despite a similar 1-year retention rate, the proportion of patients achieving DAS28-ESR remission was significantly higher in TCZ+MTX treated group compared with TNFis+MTX, suggesting a deeper clinical response in patients receiving IL 6 blockade.

References:

[1] Kristensen LE, et al. Arthritis Rheum 2006:54:600-6.

Disclosure of Interest: None declared

DOI: 10.1136/annrheumdis-2017-eular.4771
FRI0216 RESULTS OF A LONGITUDINAL REVIEW OF PULMONARY FUNCTION AND SAFETY DATA IN A PHASE IIB CLINICAL PROGRAMME TESTING GRANULOCYTE-MACROPHAGE COLONY-STIMULATING FACTOR (GM-CSF) RECEPTOR ANTAGONIST MAVRILIMUMAB FOR TREATMENT OF RHEUMATOID ARTHRITIS (RA)

G. Burmester ${ }^{1}$, M.A. Michaels ${ }^{2}$, D. Close ${ }^{3}$, A. Godwood ${ }^{3}$, K. Middleton ${ }^{3}$, P. Miranda ${ }^{4}$, J. Vencovský ${ }^{5}$, J. Kremer ${ }^{6}$, I.B. McInnes ${ }^{7}$, M. Albulescu^ ${ }^{3}$ M. Weinblatt ${ }^{\wedge} 8{ }^{1}$ Charité - University Medicine Berlin, Berlin, Germany; ${ }^{2}$ Medlmmune, Gaithersburg, United States; ${ }^{3}$ Medlmmune, Cambridge, United Kingdom; ${ }^{4}$ Centro de Estudios Reumatológicos, Santiago, Chile; ${ }^{5}$ Institute of Rheumatology, Prague, Czech Republic; ${ }^{6}$ The Albany Medical College, Albany, United States; ${ }^{7}$ University of Glasgow, Glasgow, United Kingdom; ${ }^{8}$ Brigham and Women's Hospital, Boston, United States

Background: RA is associated with pulmonary comorbidity and lung function decline over time, but longitudinal assessment of pulmonary abnormalities in the context of RA treatment needs further characterisation. Mavrilimumab, an investigational human monoclonal antibody, inhibits GM-CSF by binding to the GM-CSF receptor $\alpha$ subunit.

Objectives: To investigate the pulmonary safety of mavrilimumab because of the theoretical risk of inhibiting alveolar macrophage function and causing pulmonary alveolar proteinosis (PAP).

Methods: Pulmonary monitoring included standardised serial pulmonary function testing (spirometry and diffusing capacity of lung carbon monoxide [DLCO]), chest X-rays, assessments of dyspnoea and pulmonary adverse events (AEs) in two randomised, double-blind studies (NCT01706926; NCT01715896) where patients (pts) with moderate to severe RA received mavrilimumab 30,100 or $150 \mathrm{mg}$ every other week (eow), or placebo and mavrilimumab $100 \mathrm{mg}$ eow or golimumab $50 \mathrm{mg}$ every 4 weeks, respectively. Eligible pts transferred to the open-label extension study (NCT01712399) and received mavrilimumab $100 \mathrm{mg}$ eow. All studies excluded pts with clinically significant uncontrolled pulmonary disease. An Independent Pulmonary Evaluation Committee (IPEC), blinded to treatment, adjudicated pulmonary AEs and lung function abnormalities.

Results: Mavrilimumab was received by 442 pts with cumulative safety data exposure of approximately 900 pt-yrs and a median (range) exposure time of $2.5(0.1-3.3)$ yrs. Baseline (BL) characteristics are shown (Table). Mean dyspnoea (Table), forced expiratory volume in 1 second ( $\left.F E V_{1}\right)$, forced vital capacity (FVC) and DLCO were mostly maintained within $5 \%$ of $B L$ values for pts treated with mavrilimumab during the clinical programme. Clinically relevant decreases in predicted $\mathrm{FEV}_{1}$ and FVC ( $>20 \%$ from $\mathrm{BL}$ and $<80 \%$ predicted) were demonstrated by $\leq 6.2 \%$ of pts at any visit (Table); decreases were mostly transient with no apparent trends. Overall, 83 pts (9.24/100 pt-yrs) reported $\geq 1$ pulmonary AE; bronchitis was reported most frequently (34 pts [3.78/100 pt-yrs]); one $\mathrm{AE}$ was considered serious and treatment-related (acute bronchitis). The reported pulmonary $\mathrm{AE}$ rate was generally stable over time. No suspected or confirmed PAP cases were found by IPEC and no pulmonary-related deaths were reported.

Conclusions: We believe this is the most comprehensive longitudinal study of pulmonary function in a clinical RA programme. The BL pulmonary function profile indicates that this is not a normal population from a pulmonary health perspective. Mavrilimumab was not associated with substantial decline in pulmonary function or PAP in pts treated up to 3.3 years; its acceptable safety profile advocates initiation of Phase III studies with mavrilimumab. Further studies are now required to fully characterise pulmonary function over time in RA.

Acknowledgements: Funded by Medlmmune. Medical writing support: R Plant, QXV Comms, an Ashfield company, funded by Medlmmune.

^Senior author.

Disclosure of Interest: G. Burmester Consultant for: Medlmmune, M. Michaels Employee of: Medlmmune, D. Close Employee of: Medlmmune, A. Godwood Shareholder of: AstraZeneca, Employee of: Medlmmune, K. Middleton Employee of: Medlmmune (contracted employment at time of study), P. Miranda Grant/research support from: Amgen, Medimmune, Janssen, Pfizer, Celltrion, Abbott, Sanofi, Actelion, Merck \& Co, Boehringer, BMS, Consultant for: Pfizer [Etanecept: Fee less than USD5000], J. Vencovský Consultant for: Pfizer, Elli Lilly, MSD, Novartis, Speakers bureau: Biogen, Pfizer, MSD, Abbvie, Novartis, Boehringer, UCB, BMS, J. Kremer Shareholder of: Corrona, Grant/research support from: Abbvie, Amgen, Genentech, Lilly, Pfizer, Consultant for: Abbvie, Amgen, BMS, Genentech, Lilly, Pfizer, Employee of: Corrona, I. McInnes Grant/research support from: Medlmmune [The University of Glasgow is a charity registered in 